\title{
PENCOCOKAN GAMBAR SIDIK JARI DENGAN KAMERA HANDPHONE MENGGUNAKAN METODE RANSAC DAN TRANSFORMASI AFFINE BERBASIS ANDROID
}

\author{
Haruno Sajati ${ }^{1}$, Dwi Nugraheny ${ }^{2}$, Nova Adi Suwarso ${ }^{3}$ \\ Program Studi Teknik Informatika \\ harunosajati@stta.ac.id ${ }^{1}$, henynug@gmail.com², Novaadiso@gmail.com³
}

\begin{abstract}
Fingerprints occur due to stroke differences. These stroke differences have occurred at a time when humans are still fetal form. A normal fingerprint pattern is formed of lines and spaces. These lines are called ridges whereas the spaces between these lines are called valleys. To make an introduction to the fingerprint image requires a variety of support tools. Starting from a fingerprint machine, a smartphone that has a fingerprint sensor and much more. In this research, the acquisition of image is done by grayscaling, histogram equalization, gabor filter, binary, thinning, 8 neighbors, matching. The result of making android application with the method that has been described to show unfavorable results seen from the calculation of the accuracy of 63\%. Based on testing the specs android OS devices, this application can run on android with OS 4.4.2 specification kitkat.
\end{abstract}

Keywords : OCR Fingerprint, Fingerprint recognition, Minutiae based matching, Fingerprint image processing.

\section{Pendahuluan}

Perkembangan teknologi merupakan hal yang tidak dapat dihindari pada era ini. Teknologi berperan penting terhadap pergeseran pola kehidupan sehari-hari. Mulai dari pekerjaan yang dahulu hanya dapat dikerjakan oleh banyak orang hingga membutuhkan waktu berhari-hari dan bahkan lebih lama lagi saat ini dapat dikerjakan oleh seorang saja dengan waktu yang jauh lebih singkat.

Pengolahan citra digital telah memberikan manfaat yang banyak terhadap kehidupan manusia. Mulai dari pengenalan wajah hingga sistem presensi berbasis sidik jari. Sistem yang membutuhkan tingkat keamanan atau privasi yang tinggi dapat dibantu dengan teknologi ini.

Dalam penggunaanya teknologi pengolahan citra sidik jari membutuhkan alat penunjang yang bervariasi. Mulai dari mesin fingerprint, smartphone yang memiliki sensor sidik jari dan masih banyak lagi. Hal ini terjadi karena kualitas citra yang dihasilkan dengan kamera biasa kurang baik. Sedangkan kebutuhan manusia saat ini mulai beranjak ke mobile. Hal ini akan mempersulit pengguna jika harus memiliki devices yang mendukung teknologi ini.

Pada penelitian ini penulis akan melakukan pengujian terhadap citra sidik jari yang dihasilkan melalui kamera smartphone android. Sehingga memungkinkan proses pembacaan sidik jari dapat dilakukan dari mana saja melalui smartphone dengan spesifikasi yang minimal.

\section{Metodologi Penelitian}

Metode penelitian yang digunakan dalam penelitian ini adalah eksperimen. Metode yang akan diginakan untuk pengujian objek citra sidik jari pada penelitian ini adalah akuisisi citra, grayscalling, peningkatan kekontrasan citra dengan histogram equalization, gabor filter dan seleksi region of interest, untuk memunculkan pola garis pada citra sidik jari. Setelah pola sidik jari didapatkan kemudian dilakukan binerisasi pada pola sidik jari. Citra biner kemudian dilakukan thinning untuk menipiskan garis-garis pola sidik jari. Untuk mengekstrak minutiae yaitu ridge ending dan ridge bifurcation dilakukan pendekatan 8 ketetanggaan / neighbourhood. Setelah 
minutiae terdeteksi barulah dilakukan pencocokan. Untuk pencocokan sidik jari menggunakan metode Minutiae Based Matching menggunakan transformasi affine dan Random Sample Consensus (RANSAC).Tahap-tahap penerapan metode-metode yang digunakan pada penelitian ini dapat dilihat Gambar 1.

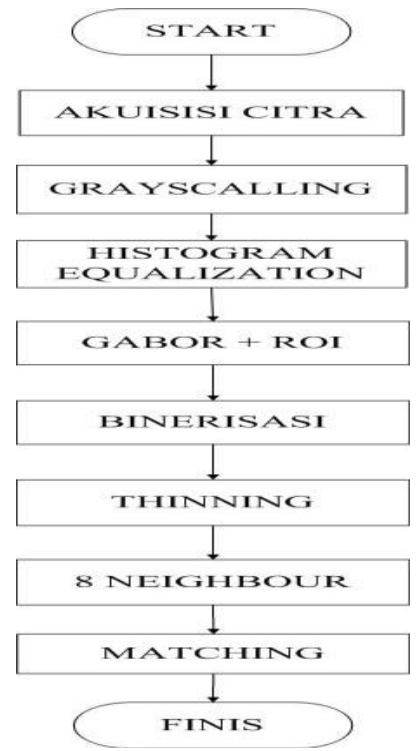

Gambar 1. Tahap- Tahap yang Digunakan Pada Peneletian

\section{A. Citra Digital}

Citra adalah gambar pada bidang dwimatra (dua dimensi). Ditinjau dari sudut pandang matematis, citra merupakan fungsi terus menerus (continue) dari intensitas cahaya pada bidang dwimatra. Sumber cahaya menerangi objek, objek ditangkap oleh alat-alat optic misalnya mata pada manusia, kamera, pemindai (scanner) dan sebagainya sehingga bayangan objek yang disebut citra tersebut terekam. Citra digital merupakan suatu larik dua dimensi atau suatu matriks yang elemen elemennya menyatakan tingkat keabuan dari elemen gambar.

\section{B. Grayscalling}

Grayscalling adalah proses penyederhanaan gambar dari format gambar berwarna RGB menjadi gambar berwarna abu-abu (gray). Suatu gambar berwarna RGB memiliki tiga lapisan matrik yaitu $R$-layer, $G$-layer dan B-layer. Bila setiap proses perhitungan dilakukan pada setiap lapisan, maka satu piksel akan dikenakan tiga kali operasi, sehingga konsep tiga layer RGB disederhanakan menjadi sebuah lapisan yaitu lapisan greyscale. Untuk mengubah gambar berwarna yang mempunyai nilai matrik masing-masing R, G dan B menjadi gambar grayscale dengan nilai $k$, maka konversi dapat dilakukan dengan mengambil rata-rata dari nilai $R, G$ dan $B$ sehingga secara mudah dapat dituliskan seperti persamaan (2).(Ardhianto, 2010)

$$
k=(R+G+B) / 3
$$

\section{Region of Interest}

Region of Interest (ROI) adalah daerah yang dipilih sebagai daerah yang paling signifikan di dalam sebuah data yang akan diidentifikasi untuk tujuan tertentu. Tujuan dari penggunaan seleksi ROI adalah memperkecil jumlah fitur citra yang akan diproses, dengan demikian akan meningkatkan kecepatan proses.

\section{Histogram Equalization}

Histogram Equalization (HE) merupakan teknik yang digunakan untuk mengatur intensitas suatu citra dengan meningkatkan nilai kontras (Gonzalez dan Woods, 2008). Cara kerja HE adalah 
dengan meratakan derajat histogram dari setiap sumbu warna. Prinsip kerjanya sangat sederhana, yaitu dengan membuat frekuensi warna lebih merata dari batas bawah ke batas atas sehingga tidak ada bagian histogram yang terlalu dominan. Di sisi lain, histogram akan membuat persebaran kumulatif gray values (dari paling gelap ke paling terang) menjadi merata dan membentuk persamaan $\mathrm{X}=\mathrm{Y}$

Untuk dapat melakukan HE ini diperlukan suatu fungsi distribusi kumulatif yang merupakan perhitungan kumulatif dari histogram. Fungsi distribusi kumulatif/cumulative distribution function (CDF).

\section{E. Gabor filter}

Filter Gabor merupakan fungsi Gaussian yang dikalikan dengan fungsi harmonik. Hal ini secara optimal terbatas sesuai prinsip ketidak pastian baik dalam frekuensi dan domain khusus yaitu $\Delta x . \Delta \omega$ yang dekat dengan $\mathrm{h}$, metrik ketidak pastian. Ini berarti bahwa Filter Gabor sangat selektif dalam kedua frekuensi dan posisi, sehingga mengakibatkan tajam tekstur deteksi batas. Paradigma segmentasi terkait dengan Filter Gabor didasarkan pada model filter bank di mana beberapa Filter diterapkan serentak ke gambar input. Filter fokus pada berbagai tertentu frekuensi. Jika gambar masukan berisi dua wilayah tekstur yang berbeda, perbedaan frekuensi lokal antara daerah akan mendeteksi tekstur dalam satu atau lebih filter output sub-gambar. Fungsi Gabor dasar dapat melakukan dekomposisi ruang sendi. Setiap Filter Gabor ditentukan oleh fungsi Gabor dasar . Karena spasial dan spasial frekuensi lokalisasi Filter Gabor secara luas digunakan untuk segmentasi tekstur, dan dituliskan

$$
g(x, y)=\exp \left(-\left(\left(\frac{a}{2 \sigma}\right)^{2}+y^{2}\left(\frac{b}{2 \sigma}\right)^{2}\right)\right) * x \cos \left(\frac{2 \pi}{\lambda}(x \cos \emptyset+y \sin \emptyset)+\emptyset\right)
$$

Dimana:

$$
\begin{aligned}
& \mathrm{a}=(\mathrm{x} \cos \theta+\mathrm{y} \sin \theta)^{2} \\
& \mathrm{~b}=(-\mathrm{x} \sin \theta+\mathrm{y} \cos \theta)^{2} \\
& \sigma=\text { bandwidth menyatakan nilai efektif dari width suatu citra } \\
& \lambda=\text { lambda menyatakan panjang gelombang suatu citra } \\
& \theta=\text { theta menyatakan sudut suatu citra } \\
& \gamma=\text { gamma menyatakan tingkat kecerahan (brightness) suatu citra } \\
& \varnothing=\text { phase menyatakan bentuk suatu citra }
\end{aligned}
$$

\section{F. Binerisasi}

Proses binerisasi adalah proses menentukan nilai ambang (Threshold). nilai ini digunakan untuk membagi citra grayscale ke dalam dua nilai yaitu hitam dan putih. Thresholding adalah metode sederhana untuk membuat gambar biner dari gambar grayscale. Dalam proses thresholding, setiap piksel dari citra digital ditandai sebagai "objek" piksel, jika nilai piksel lebih besar dibandingkan nilai ambang (Threshold) biasanya, obyek piksel diberi nilai "1" sedangkan piksel latar belakang diberi nilai "0". (Ahmad,2015)

\section{G. Thinning}

Proses thinning merupakan salah satu pemrosesan citra (image processing). Proses thinning digunakan dengan tujuan :

a. Mengurangi suatu daerah (region) menjadi suatu grafik / kurva dengan memperoleh kerangka (skeleton) dari daerah tersebut. Dengan demikian, image tersebut ditransformasikan menjadi bentuk struktural.

b. Mengurangi suatu daerah yang tebal atau bergumpal menjadi unit-unit dengan pixel-pixel tunggal. Dengan demikian, image tersebut ditransformasikan menjadi garis-garis pixel. Proses thinning merupakan salah satu pemrosesan citra (image processing). 
Proses thinning digunakan dengan tujuan :

a. Mengurangi suatu daerah (region) menjadi suatu grafik/ kurva dengan memperoleh kerangka (skeleton) dari daerah tersebut. Dengan demikian, image tersebut ditransformasikan menjadi bentuk struktural.

b. Mengurangi suatu daerah yang tebal atau bergumpal menjadi unit-unit dengan pixel-pixel tunggal. Dengan demikian, image tersebut ditransformasikan menjadi garis-garis pixel. (Suroto, 2009)

\section{H. Minutiae Extraction}

Pendeteksian minutia dilakukan dengan konvolusi 8 tetangga, yang dicari adalah akhir dari sebuah ridge (ridge ending)

dan percabangan sebuah ridge (bifurcation). Sebuah ridge didefinisikan sebagai ridge ending apabila sebuah pixel ridge $\mathrm{r}(\mathrm{i}, \mathrm{j})$ hanya memiliki 1 tetangga, sedangkan sebuah ridge didefinisikan sebagai percabangan atau bifurcation apabila pixel ridge $\mathrm{r}(\mathrm{i}, \mathrm{j})$ memiliki lebih dari 2 tetangga pixel.

\section{Matching}

Pada tahapan pencocokan (matching) digunakan penggabungan dua metode, yaitu algoritma Random Sample Consensus (RANSAC) dan metode transformasi 2 dimensi Transformasi Affine.

Random Sample Consensus (RANSAC) adalah metode iterasi untuk memperkirakan parameter dari model matematika dari sekumpulan data yang terdiri atas inliers dan outliers. Langkah pertama adalah menemukan pixel tepian, kemudian menghubungkan tepian tersebut menjadi segmensegmen kecil menggunakan metode RANSAC. Setelah itu, menggabungkan segmen menjadi garis dan menemukan semua titik potong dari semua garis yang saling tegak lurus. Langkah terakhir, menemukan dua pasang titik potong dengan jarak terjauh, maka akan didapatkan empat garis terluar marker yang merupakan langkah penting dalam mendeteksi marker. (Anisa, dkk, 2013)

Pada dasarnya transformasi afin terdiri dari unsur-unsur transformsi scaling, skewing, rotating, dan translating, masing-masing unsur transformasi tersebut dapat diilustrasikan dengan skema perubahan dimensi, bentuk, dan posisi.

\section{J. OpenCV}

OpenCV adalah sebuah library yang berisi fungsi-fungsi pemograman untuk teknologi computer vision secara real time. OpenCV sudah menggunakan antarmuka bahasa $\mathrm{C}++$ dan seluruh pengembangannya terdapat dalam format bahasa $\mathrm{C}++$. Contoh aplikasi dari OpenCV yaitu interaksi manusia dan komputer;

identifikasi, segmentasi dan pengenalan objek, pengenalan wajah, pengenalan gerakan dan penelusuran gerakan. Pada penelitain ini akan digunakan versi opencv4Android. (Fajar, 2014)

\section{K. Peralatan dan Bahan}

Dalam penelitian ini, alat dan bahan yang digunakan sebagai berikut:

1. Hardware: Smartphone Android versi 4.4.2 Kitkat

2. Software:Android development tools Eclipse, Opencv library, Android ndk

Objek: Citra sidik jari bersumber dari kamera smartphone dengan format jpg dengan ukuran $300 \times 400$.

\section{Hasil Pengamatan dan Pembahasan}

\subsection{Ketepatan Identifikasi Minutiae}

Pengujian ini bertujuan untuk melihat seberapa akuratkah metode yang digunakan dalam mengekstraksi minutiae dari citra sidik jari. Pengujian ini dapat dilakukan dengan identifikasi secara langsung terhadap citra hasil ekstraski minutiae. 
Hal yang sangat berpengaruh terhadap hasil pendeteksian minutiae adalah proses filtering minutiae. Semakin pendek jarak yang diberikan untuk mengidentifikasi suatu minutiae maka semakin banyak jumlah minutiae yang teridentifikasi. Sedangkan semakin banyak jumlah minutiae akan semakin besar kemungkinan terjadi kesalahan pencocokan karena semakin banyak pula kemungkinan pola minutiae yang sama antara citra kunci dan citra uji. Lihat pada Gambar 2.

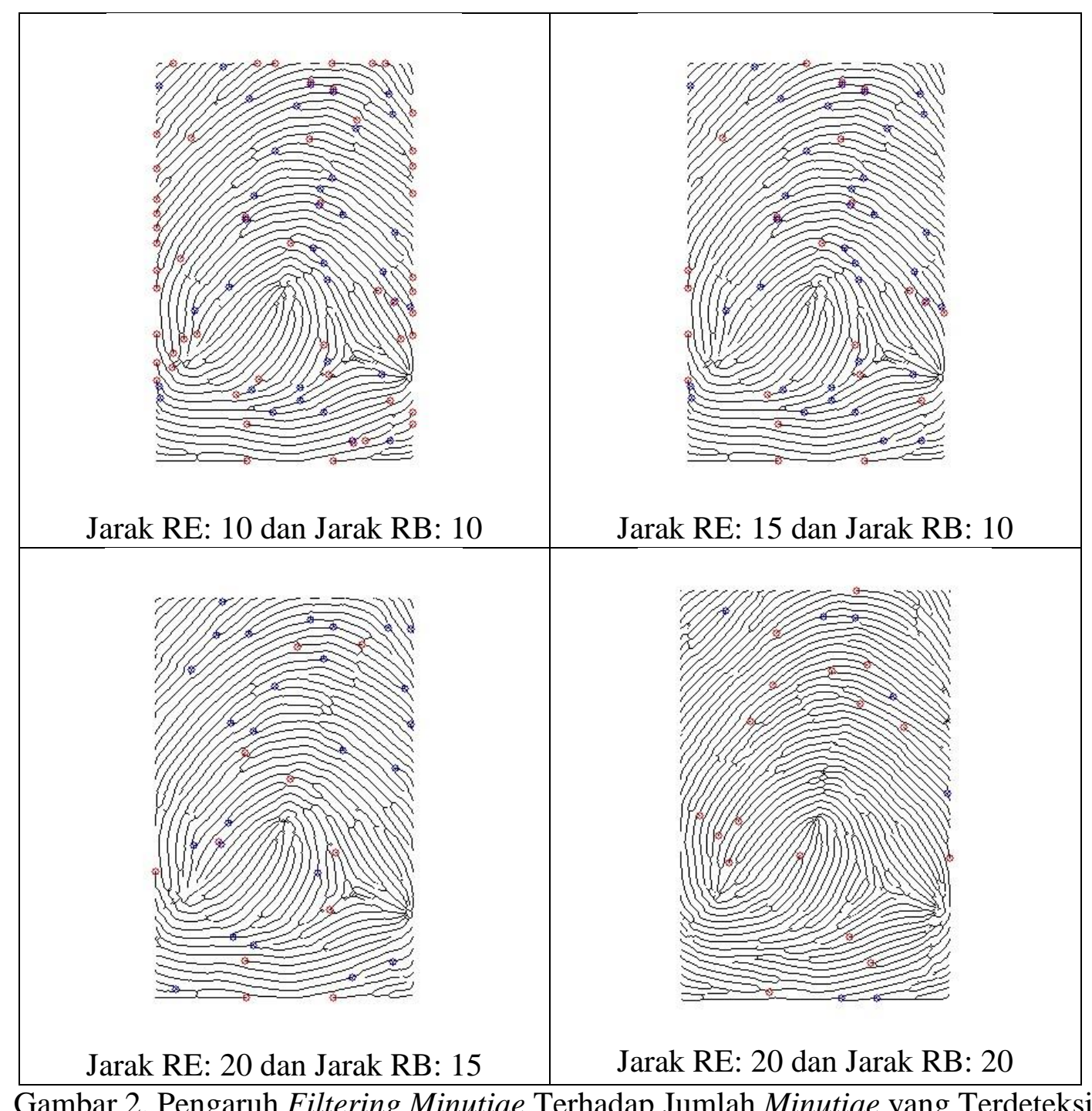

\subsection{Kemampuan Metode Dalam Mengidentifikasi Kemiripan Citra Sidik Jari}

Pada pengujian ini dilakukan pencocokan citra sidik jari dimana sebuah citra sidik jari akan dijadikan sebagai kunci atau sebagai citra database sedangkan citra lainnya digunakan sebagai citra uji. Citra yang diuji merupakan hasil dari stempel secara manual sidik jari menggunakan tinta berwarna hitam yang ditempelkan pada selembar kertas. Kemudian sidik jari yang terlihat pada kertas akan difoto satu persatu sesuai kelompok dan pemilik citra sidik jari, Hasil merupakan kemiripan dari citra kunci dan citra uji yang diproses dengan menggunakan metode RANSAC dan transformasi AFFINE. 
Hasil dari pengujian ini dapat dilihat pada Tabel 1.

Tabel 1. Hasil Pengujian

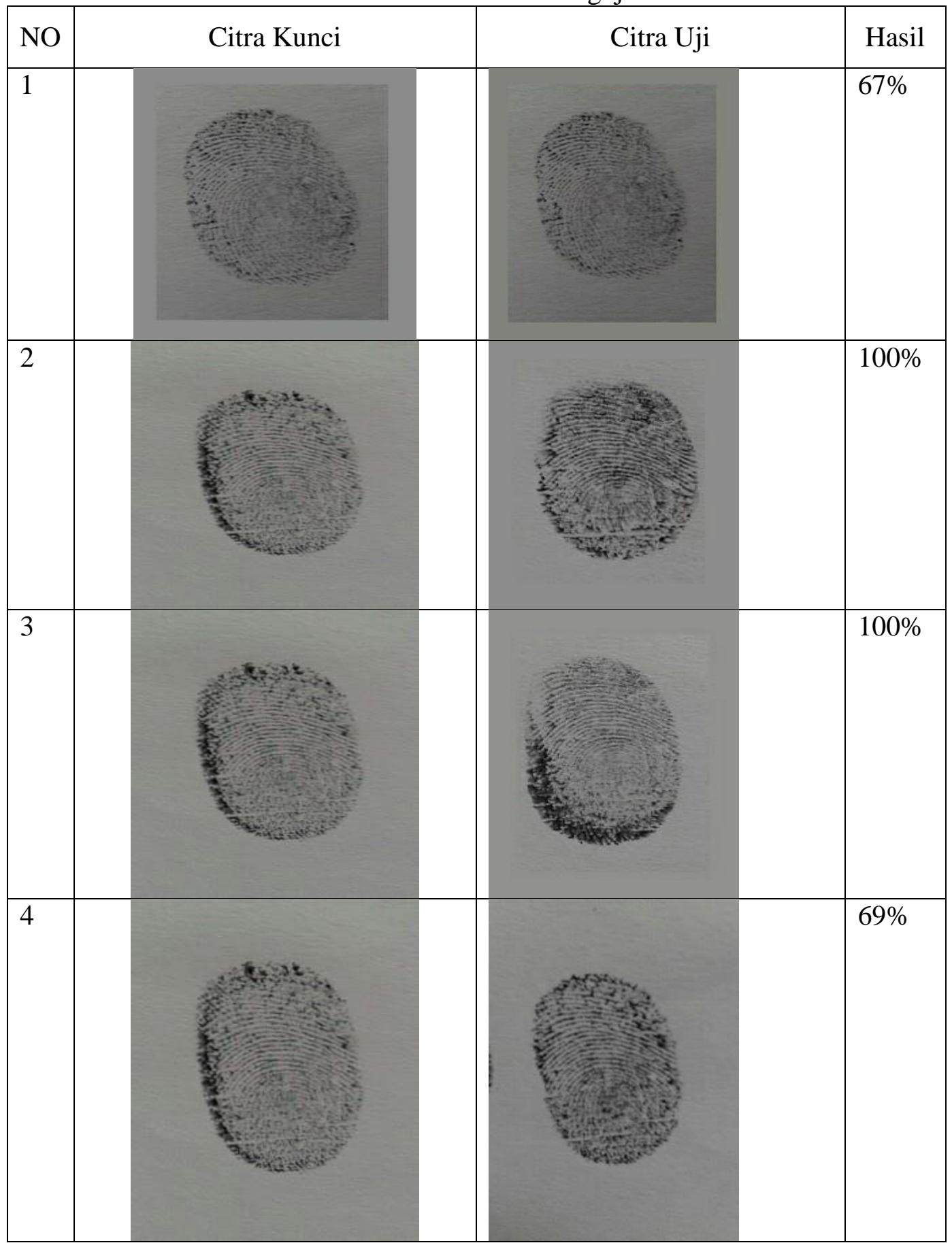

Tabel 2. Tabel perhitungan akurasi (Zhu, 2010)

\begin{tabular}{|c|c|c|}
\hline \multirow{2}{*}{ Aktual } & \multicolumn{2}{|c|}{ Pendeteksian Aplikasi } \\
\cline { 2 - 3 } Positif & Positif & Negatif \\
& $\begin{array}{c}\text { TP } \\
\text { (True Positif) }\end{array}$ & $\begin{array}{c}\text { FP } \\
\text { (False Positif) }\end{array}$ \\
\hline Negatif & $\begin{array}{c}\text { FN } \\
\text { (False Negatif) }\end{array}$ & $\begin{array}{c}\text { TN } \\
\text { (True Negatif) }\end{array}$ \\
\hline \multicolumn{3}{|c|}{ Akurasi $=\frac{T N+T P}{T N+T P+F N+F P}$} \\
\hline
\end{tabular}


Aktual adalah kepemilikan sidik jari, aktual positif adalah citra sidik jari yang dimiliki oleh satu orang yang sama sedangkan aktual negatif adalah citra sidik jari yang dimiliki oleh orang yang berbeda. Pendeteksian positif adalah kesuksesan identifikasi sidik jari sedangkan negatif adalah kegagalan identifikasi sidik jari. Kesuksesan aplikasi dilihat dari nilai kecocokan pada citra sidik jari dengan pemilik yang sama lebih besar jika dibandingkan dengan citra sidik jari dengan pemilik yang berbeda.

Pada Tabel 2 dapat dilihat hasil dari pengujian pencocokan terhadap citra sidik jari. Pada kolom Positif adalah hasil pencocokan citra sidik jari terhadap sidik jari yang sama atau orang yang sama. Sedangkan pada kolom Negatif 1, Negatif 2 dan Negatif 3 merupakan hasil pencocokan citra sidik jari terhadap sidik jari orang yang berbeda atau sidik jari yang berbeda. Kemudian hasil tersebut dibandingkan antara pencocokan terhadap sidik jari orang yang sama dan orang yang berbeda. Jika hasil dari pencocokan terhadap sidik jari yang sama lebih besar dibandingkan sidik jari yang berbeda maka hasilnya adalah true jika hasil pengujian terhadap sidik jari yang berbeda lebih besar jika dibandingkan dengan pengujian terhadap sidik jari yang sama maka hasilnya adalah false. Jumlah true dan false akan dihitung untuk mencari akurasi dari aplikasi.

Tabel 3. Hasil perhitungan akurasi

\begin{tabular}{|c|c|c|c|c|c|}
\hline $\mathrm{NO}$ & Positif (\%) & Negatif $1(\%)$ & Negatif $2(\%)$ & Negatif $3(\%)$ & HASIL \\
\hline 1 & 67 & 67 & 67 & 89 & False \\
\hline 2 & 100 & 27 & 47 & 60 & True \\
\hline 3 & 100 & 27 & 20 & 33 & True \\
\hline 4 & 69 & 20 & 33 & 27 & True \\
\hline 5 & 75 & 31 & 23 & 38 & True \\
\hline 6 & 100 & 23 & 62 & 31 & True \\
\hline 7 & 54 & 40 & 30 & 80 & False \\
\hline 8 & 80 & 23 & 100 & 57 & False \\
\hline 9 & 50 & 27 & 20 & 33 & True \\
\hline 10 & 47 & 26 & 21 & 16 & True \\
\hline 11 & 100 & 16 & 74 & 16 & True \\
\hline 12 & 80 & 21 & 37 & 26 & True \\
\hline 13 & 67 & 38 & 23 & 23 & True \\
\hline 14 & 30 & 17 & 28 & 17 & True \\
\hline 15 & 22 & 21 & 21 & 19 & True \\
\hline 16 & 60 & 18 & 14 & 14 & True \\
\hline 17 & 27 & 17 & 67 & 17 & False \\
\hline 18 & 33 & 20 & 15 & 45 & False \\
\hline 19 & 27 & 10 & 17 & 10 & True \\
\hline 20 & 67 & 50 & 20 & 15 & True \\
\hline 21 & 71 & 15 & 20 & 20 & True \\
\hline 22 & 67 & 17 & 22 & 28 & True \\
\hline 23 & 33 & 28 & 22 & 28 & True \\
\hline 24 & 48 & 15 & 12 & 50 & False \\
\hline 25 & 25 & 83 & 25 & 25 & False \\
\hline 26 & 67 & 27 & 91 & 55 & False \\
\hline 27 & 33 & 45 & 27 & 64 & False \\
\hline 28 & 16 & 7 & 11 & 7 & True \\
\hline 29 & 11 & 44 & 26 & 9 & False \\
\hline 30 & 12 & 12 & 21 & 9 & False \\
\hline
\end{tabular}

Tabel 4. Hasil Pendeteksian Aplikasi 


\begin{tabular}{|c|c|c|}
\hline \multirow{2}{*}{ Aktual } & \multicolumn{2}{|c|}{ Pendeteksian Aplikasi } \\
\cline { 2 - 3 } & Positif & Negatif \\
\hline Positif & 19 & 11 \\
\hline Negatif & 11 & 19 \\
\hline
\end{tabular}

Akurasi $=\frac{19+19}{19+19+11+11}=\frac{38}{60}=0,63$
Akurasi $=63 \%$

\subsection{Pengujian Spesifikasi Perangkat Android}

Berdasarkan percobaan pengujian aplikasi pada smartphone android, untuk menggunakan aplikasi ini agar berjalan dengan stabil pada smartphone android maka spesifikasi minimum yang dapat digunakan adalah smartphone android dengan sistem operasi Android Kitkat dan Ram 429 MB. Dapat dilihat pada hasil ujicoba Tabel 5.

Tabel 5. Hasil Uji Coba Perangkat OS

\begin{tabular}{|l|l|c|c|}
\hline NO & \multicolumn{1}{|c|}{ Versi OS } & Ya & Tidak \\
\hline 1 & Ice Cream Sandwich (versi 4.0) & & $\checkmark$ \\
\hline 2 & Jelly Bean (versi 4.1) & & $\checkmark$ \\
\hline 3 & Kitkat (versi 4.4) & $\checkmark$ & \\
\hline 4 & Lolipop (versi 5.0) & $\checkmark$ & \\
\hline 5 & Marshmallow (versi 6.0) & $\checkmark$ & \\
\hline
\end{tabular}

\section{Penutup}

\subsection{Kesimpulan}

Berdasarkan kegiatan yang telah dilaksanakan dalam penelitian ini, maka dapat diambil beberapa kesimpulan, diantaranya:

1. Metode yang digunakan pada penelitian ini dapat mendeteksi minuteae. Hal ini ditunjukan pada proses identifikasi minutiae, minutiae dapat teridentifikasi, terutama dalam hal identifikasi ridge ending (RE) maupun ridge bifurcation $(R B$.

2. Hasil dari pengenalan sidik jari menunjukkan hasil yang kurang baik. Hal ini dapat dilihat dari hasil pengujian pencocokan sidik jari. Nilai rata-rata akurasi pendeteksian sidik jari sebesar $63 \%$.

3. Berdasarkan pengujian OS, Aplikasi dapat berjalan pada smartphone android dengan OS

\subsection{Saran} minimal versi 4.4 kitkat

Dalam penelitian mengenai pengenalan sidik jari ini tidak terlepas dari beberapan kekurangan. Oleh karena itu, penulis menyarankan beberapa hal, antara lain:

1. Pengembangan terhadap metode filtering minutiae agar pengidentifikasian minutiae menjadi lebih baik.

2. Akuisisi citra sebaiknya tidak dilakukan dengan media kamera untuk memberikan citra yang lebih baik.

3. Identifikasi terhadap komponen-kompenen sidik jari dengan lebih komplek sehingga akurasi pengenalan menjadi lebih baik.

4. Lakukan pengujian dengan metode lain dalam menampilkan pola dari guratan citra sidik jari.

\section{Daftar Pustaka}

[1] Adi, Kusworo., 2003. Perancangan dan Realisasi Sistem Ekstraksi Ciri Sidik Jari Berbasis Algoritma Filterbank Gabor. Semarang: JurusanFisika, Universitas Diponegoro. 
[2] Arifin, AnisaAini., dkk. 2013. Optimasi Deteksi Marker Pada Nyartoolkit Menggunakan MetodeRansac. Malang: Universitas Brawijaya.

[3] Cahyana, Fajar MIT., 2014. Perancangan Program Penghitung Jumlah Kendaraan Di Lintasan Jalan Raya Satu Arah Menggunakan Bahasa Pemrograman C++ DenganPustakaOpencv. Malang: Universitas Brawijaya.

[4] Elia, Tiara., 2015. Aplikasi Peningkatan Kualitas Citra Menggunakan Metode Histogram Equalization. Medan: Jurusan Teknik Informatika, Sekolah Tinggi Manajemen Informatika dan Komputer.

[5] Juheri, Ahmad., 2015. Identifikasi Pola Sidik Jari Berbasis Transaformasi Wavelet dan Jaringan Syaraf Tiruan Propagasi Balik. Semarang: Jurusan Fisika, Universitas Negeri Semarang.

[6] Elvayandri. 2002. Sistem Keamanan Akses Menggunakan Pola Sidik Jari Berbasis Jaringan Saraf Tiruan. Projek Akhir Keamanan Sistem Informasi. Bandung: Institut Teknologi Bandung.

[7] Legawa, Tri.,dkk. 2011. Pengenalan Sidik Jari Menggunakan Algoritma Pencocokan Adaptif Berdasarkan Penjajaran Minutiae. Semarang: Jurusan Teknik Elektro Universitas Diponegoro.

[8] Nampira, YustiFitriyani., 2012. Aplikasi Deteksi Mikrokalsifikasi dan Klasifikasi Citra Mammogram Berbasis Tekstur Sebagai Pendukung Diagnosis Kanker Payudara. Depok: Jurusan Teknik Informatika, Universitas Gunadarma.

[9] Nasir, Muhammad., dkk.,2012. Pengujian Kualitas Citra Sidik Jari Kotor Menggunakan Learning Vector Quantization. Aceh: Jurusan Teknik Elektro, Politeknik Negri Lhokseumawe.

[10] Pangestu, Peter., 2015. Penerapan Histogram Equalization pada Optical Character Recognition Preprocessing. Tangerang: Jurusan Teknik Informatika, Universitas Multimedia Nusantara, Tangerang, Indonesia.

[11] Suroto., 2009. Studi Penyempurnaan Identifikasi Sidik Jari Pada Algoritma Minutia. Depok Jawa Barat: Jurusan Teknik Elektro, Universitas Indonesia.

[12] Tanzil, RobbinKristanto., 2015. Pengenalan Sidik Jari Menggunakan Jaringan Saraf. Surabaya: Sekolah Tinggi Teknik Surabaya.

[13] Ratnadewi.,dkk. 2004. Identifikasi Sidik jari menggunakan Metoda Modified Gabor Filter ( $M G F$ ). Bandung: FakultasTeknik, Universitas Kristen Maranatha.

[14] Zhu, Wen.,dkk. 2010. Sensitivity, Specificity, Accuracy, Associated Confidence Interval and ROC Analysis with Practical SAS® Implementations. Washington: Octagon Research Solution, Wayne, Pa. 